\title{
Assessment of Entrance Skin Dose in routine x-ray examinations of chest, skull, abdomen and pelvis of children in five selected hospitals in Nigeria.
}

\author{
${ }^{1}$ Ademola, A. K., ${ }^{2}$ Obed, R. I., ${ }^{3}$ Adejumobi, C. A., ${ }^{1}$ Abodunrin, O. P., \\ ${ }^{1}$ Alabi, O. F., ${ }^{1}$ Oladapo, M \\ 1. Department of Physical Sciences, Bells University of Technology, P.M.B. 1015, Ota, Nigeria \\ 2. Physics Department, University of Ibadan, Ibadan, Nigeria \\ 3. Department of Physics, The Polytechnic, Ibadan, Nigeria
}

\begin{abstract}
It is assumed that children are more susceptible to the effects of ionizing radiation and so deserves special attention. Entrance skin doses (ESD) and Effective dose (E) to pediatric patients were estimated during chest, skull, abdomen and pelvis examination in five Nigeria hospitals using DoseCal software. The mean ESD for Chest (PA) in age range $1-5$ in the five hospitals (H1 - H5) were 70, 139, 130, 105 and $111 \mu \mathrm{Gy}$, respectively. The median ESD values in all the examinations were compared with the NRPB and EC reference level and were found to be lower except for Chest PA and Chest Lateral examinations. The mean effective doses were compared with those found in literature and were found to be comparable. Data shows that there is variation in the result of the ESD obtained and so adherence to guidelines should be demonstrated
\end{abstract}

Keywords; ESD, x-rays, effective dose, ionizing radiation

\section{Introduction}

Medical x-ray is by far the largest man-made source of exposure to ionizing radiation ( $\mathrm{Ng}$ et al, 1998). The average dose to the population from medical exposure is estimated to be about $0.2-2 \mathrm{mSv}$ per year in industrialized countries (UNSCEAR, 2000). The International Commission on Radiological Protection (ICRP) in its 1990 recommendation (ICRP, 1990) recommended that all medical exposures should be subjected to the radiation safety principle of justification and optimization and in 1992, the National Radiation Protection Board (NRPB, 1992) recommended reference doses against which individual center could compare their performances. Radiation protection is of particular importance in pediatric radiology because of the higher sensitivity of tissues in children and adolescent and relatively longer life expectancy of young patients that may increase the chance of the development of radiogenic cancer (Neitzer, 2004). Justification of radiological requests, standardization of procedures and optimization of protection measures are key principles in the protection of individuals exposed to ionizing radiation for diagnostic purposes and it is in nowhere more pertinent than in the imaging of children (Cook et al 2001). The effects of exposure to ionizing radiation are dependent on age at which exposure occurs (Mohamadian et al 2004). Therefore close attention should be paid to improve the diagnostic information and to reduce the children doses as much as possible.

In Nigeria, researches on children radiation dose in routine $\mathrm{X}$-ray examinations are scanty. Ogundare et al, 2004 carried out research on children radiation dose in routine X-ray examination and it was discovered that there are wide variations in dose from hospital to hospital which need to be corrected.

The aim of this study is to estimate Entrance Skin Dose (ESD) in pediatric patients arising from x-ray examinations of the chest, pelvis, abdomen and pelvis in five selected hospitals in Nigeria. Data from these measurements will serve as a useful baseline against which measurements at individual x-ray departments may be compared and also as an investigation of the possibility of further reduction in patients' doses. This study will also serve as review of children dose in Nigeria because no such research had been conducted in the last five years.

\section{Materials and Methods.}

This study was carried out in five hospitals in southwestern, Nigeria. All the x-ray machines used in these hospitals are analogue and are used with antiscatter radiation grid in all examinations. Extensive quality control was performed to evaluate $\mathrm{kVp}$ accuracy in the hospitals. Filtration check and darkroom evaluation tests were also performed in each hospital. The Film-screen speed was 400 in all the hospitals surveyed. The operating potential used for each radiographic examination was determined based on the type of examination, patient's weight and thickness. The qualities of image were compared among the hospitals and were found acceptable for diagnostic purposes. Acceptability of diagnostic images is purely personal and were assessed by the radiographers.. The age range/interval considered were: $0-1,1-5,5-10$ and 10-15 years. These intervals were 
chosen since results in literature follows the protocol (Azevedo et al, 2006, Mohamadian et al, 2004, NRPB 2000 and European Commission, 1996b). The six projections considered were Chest (AP and Lat), Skull (AP and Lat), Pelvis (AP) and Abdomen (AP). Data were collected for 450 pediatrics patients that is 15 patients from each hospital and for each projection considered as recommended by (NRPB, 1992). For each patient, age, sex, weight, height and thickness are recorded and corresponding technical parameters of exposures $(\mathrm{kV}, \mathrm{mAs}$ and focus to skin distance FSD) were recorded.

Although the National Radiological Protection Board (NRPB, 1992) recommended that measurement of patients' dose be directly measured on Thermo-Luminescent Dosimeters (TLDs), free-air measurement of a tube's radiation output together with the calculation of Entrance Skin Dose using standard factors can also be employed in appropriate circumstances. (Davies et al, 1997). In this work, we employed calculation of entrance skin dose (ESD) based on standard exposure data due to unreadily availability of TLD chips and TLD reader in Nigeria and also because the study of Davies et al., showed that ESDs calculated using DoseCal software are within 20\% compared with ESDs measured using thermo luminescence dosimeters (TLDs). DoseCal software was developed by the radiological protection centre of Saint George' Hospital, London, this software was extensively used to calculate patient doses in diagnostic radiology (Suliman and Elsiekh, 2008). The software is specially developed for the evaluation of ESD (DoseCal) based on equation 1.

$$
E S D=\text { Output } \times\left(\frac{k V}{80}\right)^{2} \times\left(\frac{100}{F S D}\right)^{2} \times m A s \times B S F
$$

The output is the output in $\mathrm{mGy} / \mathrm{mAs}$ of the X-ray tube at $80 \mathrm{kV}$ at a distance $100 \mathrm{~cm}$ normalized to $10 \mathrm{mAs}$. BSF is backscatter factor for a particular examination at the required potential and was taken from NRPB numerical simulations. The Output was measured using calibrated ionization chamber; Radcal Model 2025. Effective dose was estimated using the dose conversion coefficient (NRPB Report 262) which depends on the radiographic procedures (tube potential and filtration $(\mathrm{mm} \mathrm{Al})$ and projections studied.

\section{Results And Discussion}

This study cover 450 pediatric patients intentionally selected from 756 patients monitored in five hospitals in Nigeria between February 2009 and June, 2012. 15 patients were selected for each projection in each hospital. The patients' information and exposure technical parameters for the six projections considered are tabulated according to age groups and were presented in Table 1 with the range in bracket. There is wide variation in technical parameters ( $\mathrm{kVp}$ and $\mathrm{mAs})$ used in these hospitals, which shows that there is no standard of procedure. For example, mAs vary from 5-12 mAs for chest PA in age range 1-5 year and vary from 5-55 mAs for chest lateral in age range $5-10$ year. The results of statistical ESD for all the six projections considered across all the age range were presented in Table 2. The mean, minimum, maximum and median obtained for each projection were presented. The range of dose for Chest PA projection for age range (1-5) is $84-159 \mu \mathrm{Gy}$ with a mean of $111 \mu \mathrm{Gy}$, for age range $5-10$, the range is $145-165 \mu \mathrm{Gy}$ with mean of $159 \mu \mathrm{Gy}$ and for age range $10-15$, the range is $280-1590 \mu \mathrm{Gy}$ with a mean of $620 \mu \mathrm{Gy}$. Table 3 presented the values of ESD and E obtained for the six projections considered for the specified age ranges. The mean ESD in chest PA for the age range $1-5$ was estimated to be $111 \mu \mathrm{Gy}$ which is higher than the reference level of 70 and $100 \mu \mathrm{Gy}$ recommended by NRPB and EC, respectively. The mean ESD for age range 5-10 year for chest PA is $159 \mu \mathrm{Gy}$ which is higher than $120 \mu \mathrm{Gy}$ recommended. The comparison of mean ESD in the five hospitals for all chest PA projections for age range 1-5 is shown in Figure 1. Chest PA examination was chosen for showing the comparison in the five hospitals because it's the most frequent examination in all the hospitals and even worldwide. NRPB 2000 reference levels and European commission reference levels are used as reference to compare the results of ESD obtained. ESD is generally below reference levels in hospital $\mathrm{H1}$ as compared to hospitals $\mathrm{H} 2-\mathrm{H} 5$ in the study. The reasons for the variation in ESD may be due to performance of equipment, type of $\mathrm{x}$-ray generator, the processing system and radiographic techniques used in these hospitals. According to NRPB 2000, the reference levels are given in defined age that is (newborn, 1 year, 5 years, and 10 years). For example, for AP and PA chest radiographs; $50 \mu \mathrm{Gy}$ for newborns and 1 year old, $70 \mu \mathrm{Gy}$ for 5 years and 120 $\mu \mathrm{Gy}$ for 10 years old children. It is difficult to compare this reference with the results of this study where age range had been used to evaluate the mean ESD values but can still provide useful information for comparison.

\section{Conclusion}

Entrance skin doses (ESD) of pediatric patients undergoing chest (PA and Lat), skull (AP and Lat), abdomen (AP) and pelvis (AP) examinations in five Nigerian hospitals have been monitored. The individual ESD values were observed to be consistent with the range of values that have been reported in past studies. The median values of the present study are compared with reference levels in literature and the values in this present study are mostly comparable. 
The median ESD values in all the examinations were also compared with the reference level recommended by NRPB and European Commission. The results were found to be lower in all other projections except for Chest PA and Chest Lateral examinations which is most performed radiograph in Nigeria (about $56 \%$ of the total patient). The mean effective doses when compared with those found in literature (Aroua et al 2002) are lower. This mean that the radiation risk to an average patient in the hospitals included in this work is low and the risk to workers in the hospitals will be generally low. Although the mean effective dose is lower than the reference levels, data shows that ESD is still above reference levels in some hospitals. Therefore adherence to guidelines should be demonstrated and it is also important to correct operative modalities, which will enable doses to become lower while quality of image is still preserved.

Finally, the study of local diagnostic reference levels (LDRL) is important so that users can compare their work and change their attitude and philosophy for the one that is safer to the staff and the patients

\section{References}

[1]. Aroua, A, Decka, I, Burnard B, Vader JP and Valey JF (2002): Dosimetric Aspects of a National Survey of Diagnostic and Interventional Radiology in Switzerland. Med. Phys. 29, 2247-2251

[2]. Azevedo, A C P, Osibote A.O and Boechat M.C.B (2006). Pediatric X-ray examination in Rio de Janeiro; Phy. Med. Biol. 51; 3723-3732

[3]. Cook, J V, Kyriou, J C, Pettet, A, Fitzgerald, M C, Shah, K, and Pablot, S.M.(2001): Key factors in the optimization of pediatric X-ray practice. Br. J Radiol 2001; 74, 1032-1040

[4]. Davies M. McCallum H, White G, Brown J and Hlem M (1997): Patient dose audit in diagnostic radiography using custom designed software: Journal of Radiography; Vol 3: $17-25$.

[5]. European commission (EC) 1996b: European guidelines of quality criteria for diagnostic radiographic images in pediatrics. EUR 16261 EN, July 1996.

[6]. Hart D, Jones DG and Wall BF, 1994. Estimation of effective dose in diagnostic radiology from entrance surface dose and dosearea product measurements. NRPB Report R262. NRPB, Chilton.

[7]. International Commission on Radiological Protection (1990): Recommendation of the International Commission on Radiological Protections, Annals of ICRP Vol. 21. Publication 60.

[8]. Mohamadian K.E.M, Da Rosa LAR, Azevedo A,C, Guebel M.R.N, Boechat M.C.B and Habani, F (2004): Dose evaluation for Pediatric Chest X-ray examination in Brazil and Sudan: Low doses and reliable examination can be achieved in developing Countries. Med. Phys. Vol. 49:1017-1031.

[9]. National Radiological Protection Board (1992): National protocol for patient dose measurements in diagnostic radiology dosimetry: Report of a working party of the Institute of Physical Sciences in Medicine

[10]. National Radiation Protection Board (2000) (pediatric): Reference doses and patient size in pediatric radiology. NRPB- R318, 2000

[11]. Neitzer, U (2004): Pediatric radiation dose management in digital radiography. Pediatric Radiology. 34 (Suppl. 3 ) $227-233$.

[12]. Ng K-H, Rassiah P, Wang H.B, Hambali A.S, Muthuveliu P and Lee H.P (1998). Dose to patient in routine x - ray examination in Malaysia: British journals of radiology Vol: 71: 654- 660

[13]. Ogundare, FO, Ajibola, CL and Balogun FA (2004). Survey of radiological techniques and doses of children undergoing some common x-ray examinations in three hospitals in Nigeria. Med.Phys. 31 (3) 521-524.

[14]. Suliman I.I. and E.H.A. Elshiekh (2008) Radiation Protection Dosimetry; 132(1), 64-72

[15]. United Nation Scientific Committee on the Effects of Atomic Radiation. Sources and Effects of Ionizing Radiation. 2000 report to the General Assembly: with Scientific Annexes (United Nation, New York, 2000)

Table 1: Patients information and exposure parameters for the six projections considered. (Range in parenthesis)

\begin{tabular}{|c|c|c|c|c|c|c|}
\hline & Radiograph & Projection & Age & Weight $(\mathrm{Kg})$ & $\mathrm{kVp}$ & $\mathrm{mAs}$ \\
\hline \multirow[t]{6}{*}{$1-5$} & \multirow[t]{2}{*}{ Chest } & PA & $4(2-5)$ & $24(20-28)$ & 50 & $8(5-12)$ \\
\hline & & Lat & $3.5(3-4)$ & $24(20-28)$ & 55 & 5 \\
\hline & \multirow[t]{2}{*}{ Skull } & AP & $2(2)$ & 20 & 75 & 5 \\
\hline & & Lat & $2(2)$ & 20 & 70 & 5 \\
\hline & Abdomen & AP & $1.5(0-3)$ & $5(3-8)$ & $73(60-85)$ & 5 \\
\hline & Pelvis & AP & $5(5)$ & 30 & 70 & 5 \\
\hline \multirow[t]{6}{*}{$5-10$} & Chest & PA & $8(6-10)$ & $30(26-32)$ & 50 & 15 \\
\hline & & Lat & $8(6-10)$ & $26(25-28)$ & $47(33-55)$ & $22(5-55)$ \\
\hline & Skull & AP & $8(6-10)$ & 32 & 60 & 25 \\
\hline & & Lat & $8(6-10)$ & 32 & 50 & 20 \\
\hline & Abdomen & AP & 9 & 32 & 50 & 22 \\
\hline & Pelvis & AP & $7(5-10)$ & 36 & 60 & 30 \\
\hline \multirow[t]{6}{*}{$10-15$} & Chest & PA & $14.5(14--15)$ & 50 & 70 & 5 \\
\hline & & Lat & 13 & 42 & 60 & 15 \\
\hline & Skull & AP & $14.5(14-15)$ & $30(26-35)$ & 80 & 25 \\
\hline & & Lat & $14.5(14-15)$ & $30(26-35)$ & 80 & 20 \\
\hline & Abdomen & AP & $12(11-15)$ & $35(25-45)$ & 80 & 30 \\
\hline & Pelvis & AP & $13(12-14)$ & 40 & 60 & 30 \\
\hline
\end{tabular}


Table 2: Statistical distribution of ESD (in $\mu \mathrm{Gy}$ ) for the six projections and the age ranges.

\begin{tabular}{llllllllllllll}
\hline Age Range & \multicolumn{1}{l}{ Chest(PA) } & \multicolumn{2}{c}{ Chest(Lat) } & \multicolumn{3}{l}{ Skull(AP) } & \multicolumn{3}{c}{ Skull(Lat) } & \multicolumn{3}{c}{ Abdomen(AP) } & \multicolumn{2}{c}{ Pelvis(AP) } \\
& ESD & E & ESD & E & ESD & E & ESD & E & ESD & E & ESD & E \\
\hline $0-1$ & - & - & - & - & - & - & - & - & - & - & - & - \\
$1-5$ & 111 & 6.3 & 170 & 9.7 & 660 & 7.9 & 570 & 5.7 & 310 & 37 & 570 & 75 \\
$5-10$ & 159 & 18 & 235 & 8.9 & 741 & 4.5 & 650 & 3.9 & 351 & 28.1 & 854 & 112 \\
$10-15$ & 620 & 68.8 & 286 & 15.7 & 856 & 9.4 & 995 & 11.9 & 800 & 60.8 & 1354 & 181 \\
\hline
\end{tabular}

Table 3: The mean values of ESD and E obtained in this study for specified patient ages and types of examinations

\begin{tabular}{lllllll}
\hline Radiograph & Projection & $\begin{array}{l}\text { Mean } \\
\text { ESD } \\
(\mu \mathrm{G})\end{array}$ & Min & Max & Median \\
\hline 1-5 & Chest & PA & 111 & 84 & 159 & 129 \\
& & Lat & 170 & 107 & 179 & 147 \\
& Skull & AP & 660 & 460 & 1220 & 870 \\
& & Lat & 570 & 380 & 620 & 430 \\
& Abdomen & AP & 310 & 260 & 360 & 310 \\
5 5-10 & Pelvis & AP & 570 & 500 & 590 & 550 \\
& Chest & PA & 159 & 145 & 165 & 155 \\
& Skull & Lat & 235 & 170 & 688 & 170 \\
& & AP & 741 & 650 & 805 & 750 \\
& Abdomen & AP & 650 & 580 & 785 & 670 \\
$10-15$ & AP & 351 & 301 & 380 & 330 \\
& Celvis & AP & 854 & 750 & 1085 & 725 \\
& Chest & PA & 620 & 280 & 1590 & 940 \\
& Skull & Lat & 286 & 268 & 300 & 286 \\
& AP & 856 & 730 & 1320 & 980 \\
& Abdomen & Lat & 995 & 735 & 1395 & 1050 \\
& Pelvis & AP & 800 & 650 & 940 & 830 \\
& & & 1354 & 850 & 1850 & 1220 \\
\hline
\end{tabular}

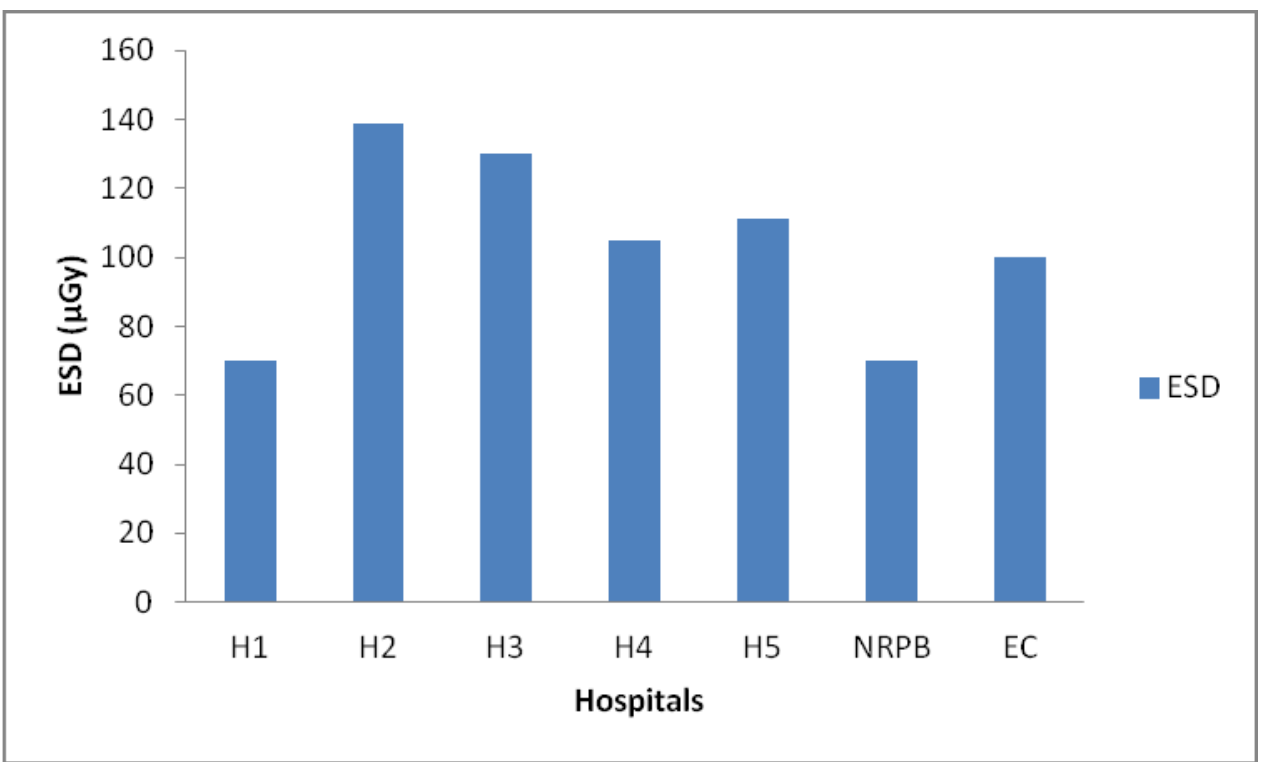

Figure 1: Comparison of the mean values of ESD in the five hospitals with reference levels from NRPB and EC 